\title{
7-Chloroquinolin-4-yl Arylhydrazone Derivatives: Synthesis and Antifungal Activity
}

\author{
Auri R. Duval ${ }^{1}$, Pedro H. Carvalho ${ }^{2}$, Maieli C. Soares ${ }^{1}$, Daniela P. Gouvêa ${ }^{1}$, \\ Geonir M. Siqueira ${ }^{1}$, Rafael G. Lund ${ }^{2}$, and Wilson Cunico ${ }^{1, *}$ \\ ${ }^{1}$ NuQuiA - Núcleo de Química Aplicada, Centro de Ciências Químicas, Farmacêuticas e \\ de Alimentos (CCQFA), Universidade Federal de Pelotas, Campus Universitário, Pelotas, \\ RS, Brazil; ${ }^{2}$ Laboratório de Microbiologia Oral, Faculdade de Odontologia, Universidade \\ Federal de Pelotas, Pelotas, RS, Brazil \\ E-mail: wjcunico@yahoo.com.br
}

Received May 4, 2011; Revised July 22, 2011, Accepted July 22, 2011; Published July 28, 2011

Fifteen 7-chloro-4-arylhydrazonequinolines have been evaluated for their in vitro antifungal activity against eight oral fungi: Candida albicans, $C$. parapsilosis, $C$. lipolytica, C. tropicalis, C. famata, C. glabrata, Rhodutorula mucilaginosa, and R. glutinis. Several compounds exhibited minimum inhibitory concentration (MIC) and minimum fungicidal concentration (MFC) activities comparable with the first-line drug fluconazole. These results could be considered as an important starting point for the rational design of new antifungal agents.

KEYWORDS: antifungal drugs, hydrazones, thiazolidinones, microbial sensitivity tests

\section{INTRODUCTION}

Candida albicans is a yeast-like dimorphic fungus that can be found as part of the normal flora in the mouth, feces, and vaginal secretions of adults[1]. The progression of the infection in mucous membranes was referred as a process that depends on the host defense and on the ability of Candida spp. to overcome this defense mechanism[2]. Chronic atrophic (erythematous) candidiasis, also known as "denture stomatitis", is a clinical presentation of oral candidiasis, especially in the elderly and particularly in those who wear dentures and do not present good mouth care regimen[3]. Rhodotorula spp. of the Criptococcaceae family are common airborne organisms that may be present on the skin and in sputum, urine, and feces. Furthermore, they are commonly isolated from patients with denture stomatitis and have been implicated as an infrequent cause of infections, such as septicemia, endocarditis, meningitis, and peritonitis. To date, most infections caused by Rhodotorula spp. have been associated with intravenous catheters and with patients who have solid tumors, lymphoproliferative diseases, chronic renal failure, diabetes, endocarditis, pulmonary diseases, and AIDS. Because of the intrinsic resistance of Rhodotorula spp. to the triazoles and echinocandins, patients that receive fluconazole and caspofungin are susceptible to develop breakthrough Rhodotorula fungemia[4]. 
Unfortunately, the use of the limited numbers of antifungal agents to treat fungal infections has led to the development of drug resistance. Hence, the development of new antifungal drugs should be encouraged.

Hydrazones are an important intermediate group for the synthesis of a large number of compounds, especially heterocyclic thiazolidinones. Thiazolidinones are five-membered heterocycles with one nitrogen atom, one sulfur atom, and a carbonyl group, which have valuable biological activities[5]. The literature shows the potential antimicrobial activity of hydrazones[6,7,8,9], and due to synthetic and biological versatility of such compounds, they are attractive target compounds for new drug development[10].

The 7-chloroquinoline moiety was extensively studied, mainly for its antimalarial properties[11,12]. In this context, we studied the application of 7-chloro-4-hydrazinoquinoline as a precursor to the synthesis of (trifluoromethyl-1H-pyrazol-1-yl)chloroquine analogues and the biological study of such heterocycles against Plasmodium falciparum[13]. Recently, some 7-chloro-4-hydrazonequinoline derivatives have also been investigated as antitubercular agents[14,15] and in the course of our investigations on the chemistry of five-membered heterocyclic thiazolidinones[16,17,18], the aims of this work were the synthesis and antifungal activities of 7-chloro-4-arylhydrazonequinolines $\mathbf{4 a - 0}$ and their application as precursors to the synthesis of thiazolidinones.

\section{RESULTS AND DISCUSSION}

The synthetic route for the preparation of 7-chloro-4-arylhydrazonequinoline derivatives is summarized in Scheme 1. The reaction of 4,7-dichloroquinoline with hydrazine hydrate $(80 \%)$ in reflux of absolute ethanol for $4 \mathrm{~h}$ gave 7-chloro-4-hydrazinoquinoline 2 in good yields[19]. In our study, we initially isolated the hydrazone intermediates $\mathbf{4 a - 0}$, refluxing the 7-chloro-4-hydrazinoquinoline $\mathbf{2}$ with arenealdehydes 3a-o in toluene with water removal using a Dean-Stark apparatus (Scheme 1). After the reaction time, the solvent was removed and the products were obtained in near quantitative yields (9298\%). Hydrazones $\mathbf{4 a - 0}$ were identified by ${ }^{1} \mathrm{H}$ NMR and by melting points, and are in agreement with the literature data[14,20].

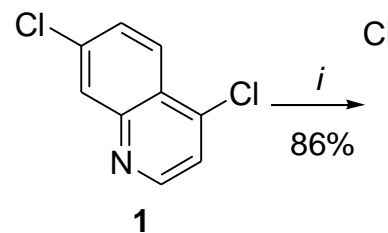

1<smiles>NNc1ccnc2cc(Cl)ccc12</smiles>

2

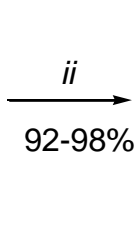

$2-98 \%$

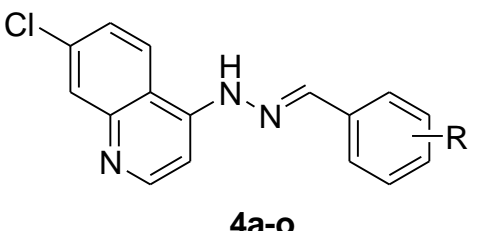

4a-0

i: $\mathrm{NH}_{2} \mathrm{NH}_{2} \cdot \mathrm{H}_{2} \mathrm{O}$ (80\%), MeOH, reflux, $4 \mathrm{~h}$

ii: arenealdehyde $3 \mathrm{a}-\mathbf{0}$, toluene, reflux, $3 \mathrm{~h}$

\section{SCHEME 1.}

Subsequently, the reaction of hydrazones $\mathbf{4 a - 0}$ with an excess of mercaptoacetic acid was carried out in reflux of toluene for long reaction times $(24-72 \mathrm{~h})$. To our surprise, the expected heterocyclic thiazolidinones were not obtained and the precursors were fully recovered. A possible explanation is the low solubility of hydrazones in toluene; however, even when we carried out the reaction in dimethylsulfoxide (DMSO) at $120^{\circ} \mathrm{C}$ for long time periods, no thiazolidinones were formed. Recently, we published an improved methodology to synthesize thiazolidinones from hydrazones using only mercaptoacetic acid as solvent[21]. However, in this condition and even using ultrasound irradiation[22], the desired heterocycle was not observed by TLC or GC. 
Table 1 shows the antifungal activities of compounds $\mathbf{4 a - 0}$ expressed as minimum inhibitory concentration (MIC) and minimum fungicidal concentration (MFC) against eight $C$. albicans strains. Two compounds (4a and 4o) exhibited antifungal activity in comparison with the standard drug fluconazole and the hydrazone $4 \mathbf{a}(\mathrm{R}=2-\mathrm{F})$ showed the highest activities ( $\mathrm{MIC}=25 \mu \mathrm{g} / \mathrm{mL}$ and $\mathrm{MFC}=50 \mu \mathrm{g} / \mathrm{mL}$ ). For hydrazones $\mathbf{4 b}-\mathbf{n}$ the MIC and MFC values were higher than $200 \mu \mathrm{g} / \mathrm{mL}$, thus considered inactive. These results might indicate that the presence of a small fluorine atom on the 2-position of the benzene ring seems to be important for the antifungal activity since the chlorine atom (4d) did not show antifungal activity.

TABLE 1

Antifungal Activity of Hydrazones $4 a-0$ against Eight $C$. albicans Strains $(\mu \mathrm{g} / \mathrm{mL})$

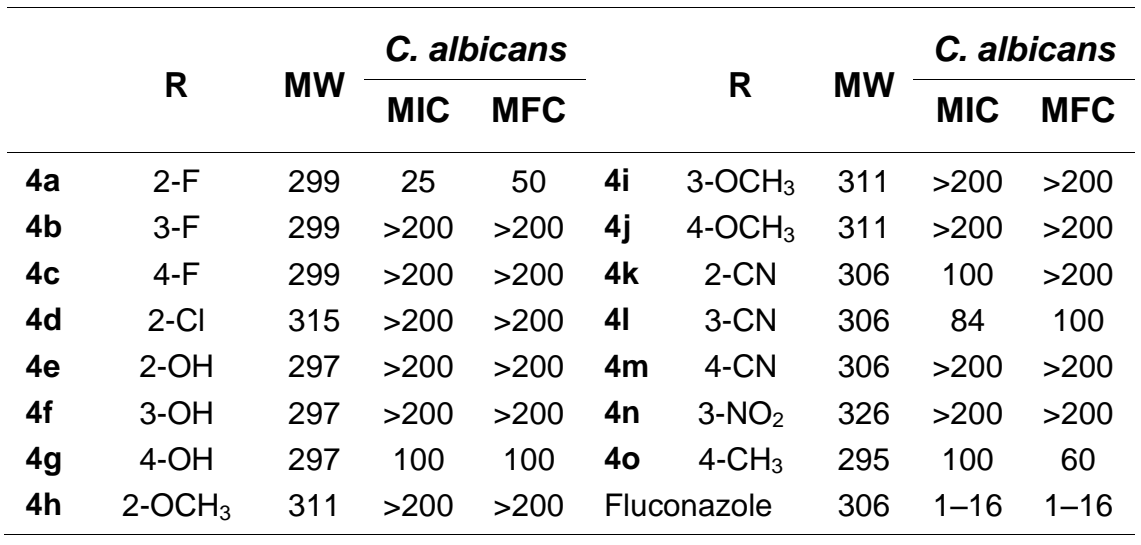

The values are the mean of at least three determinations.

We explored in more detail the antifungal potential of the hydrazones $\mathbf{4 a}, \mathbf{4 g}, \mathbf{4 l}$, and $\mathbf{4 0}$. These four compounds were also tested against the following fungi: $C$. parapsilosis (three strains); C. lipolytica (two strains); and C. tropicalis, C. famata, C. glabrata, Rhodutorula mucilaginosa, and $R$. glutinis (one strain). Compound 4a showed good activity (MIC $=50 \mu \mathrm{g} / \mathrm{mL}$ and $\mathrm{MFC}=50 \mu \mathrm{g} / \mathrm{mL}$ ) against four fungi (Table 2); however, this compound was cytotoxic on mouse fibroblast cells. At a concentration of $50 \mu \mathrm{g} / \mathrm{mL}$, cell viability was reduced by $92 \%$ after $24 \mathrm{~h}$ of incubation (Table 3). Hydrazones $\mathbf{4 g}$ and $\mathbf{4 l}$ did not show good antifungal activity (Table 2) and they were also cytotoxic (Table 3). Hydrazone $4 \mathbf{o}\left(\mathrm{R}=\mathrm{CH}_{3}\right)$ showed the best MIC and MFC values ( $40 \mu \mathrm{g} / \mathrm{mL}$ ) for all fungi, with the exception of $C$. tropicalis (Table 2), and also showed low cytotoxicity ( $82 \%$ of cell viability at $50 \mu \mathrm{g} / \mathrm{mL}$ after $24 \mathrm{~h}$, Table 3 ). The MIC value against $R$. glutinis of the most active compound $4 \mathbf{o}$ was comparable to that of fluconazole (MIC $=32 \mu \mathrm{g} / \mathrm{mL}$ ).

\section{CONCLUSION}

The intermediate hydrazones $\mathbf{4 a - 0}$ were easily synthesized in excellent yields. The corresponding thiazolidinones were not obtained from hydrazones; however, hydrazones $\mathbf{4 a - 0}$ possess potential biological applications. In this work, we explored the antifungal activity of all hydrazones against $C$. albicans and one of them, 4a, exhibited a MIC value of $25 \mu \mathrm{g} / \mathrm{mL}$ and a MFC value of $50 \mu \mathrm{g} / \mathrm{mL}$. The compounds $\mathbf{4 a}, \mathbf{4 g}, \mathbf{4 l}$, and 40 were also tested against five other yeasts species of Candida and two yeasts species of Rhodutorula. The hydrazone 4o showed the lowest MIC and MFC values $(40 \mu \mathrm{g} / \mathrm{mL})$. The most active compound, 4o, showed similar antifungal activity against $R$. glutinis when compared to fluconazole. These results could be considered an important starting point to develop new antifungal agents. 
TABLE 2

Antifungal Activity of Hydrazones $4 \mathrm{a}, \mathbf{4 g}, 4 \mathrm{I}$, and 40 Expressed as MIC and MFC in $\mu \mathrm{g} / \mathrm{mL}$

\begin{tabular}{|c|c|c|c|c|c|c|c|c|c|c|c|c|c|c|c|}
\hline & \multirow{2}{*}{$\mathbf{R}$} & \multicolumn{2}{|c|}{$\begin{array}{c}R . \\
\text { glutinis }\end{array}$} & \multicolumn{2}{|c|}{$\begin{array}{c}R . \\
\text { mucillaginosa }\end{array}$} & \multicolumn{2}{|c|}{$\begin{array}{c}\text { C. } \\
\text { glabrata }\end{array}$} & \multicolumn{2}{|c|}{$\begin{array}{c}C . \\
\text { parapsilosis }\end{array}$} & \multicolumn{2}{|c|}{$\underset{\text { famata }}{C .}$} & \multicolumn{2}{|c|}{$\begin{array}{c}\text { C. } \\
\text { lipolytica }\end{array}$} & \multicolumn{2}{|c|}{$\begin{array}{c}\text { C. } \\
\text { tropicalis }\end{array}$} \\
\hline & & MIC & MFC & MIC & MFC & MIC & MFC & MIC & MFC & MIC & MFC & MIC & MFC & MIC & MFC \\
\hline $4 a$ & $2-\mathrm{F}$ & 50 & 50 & 50 & 50 & $>200$ & $>200$ & 50 & 50 & $>200$ & $>200$ & 50 & 50 & 100 & 100 \\
\hline $4 g$ & $4-\mathrm{OH}$ & $>200$ & $>200$ & 87 & 100 & 87 & 100 & 87 & 100 & $>200$ & $>200$ & 87 & 100 & $>200$ & $>200$ \\
\hline 41 & $3-\mathrm{CN}$ & $>200$ & $>200$ & 84 & 100 & $>200$ & $>200$ & 84 & 100 & $>200$ & $>200$ & 84 & 100 & 84 & 100 \\
\hline 40 & 4- $\mathrm{CH}_{3}$ & 40 & 40 & 40 & 40 & 40 & 40 & 40 & 40 & 40 & 40 & 40 & 40 & 80 & 80 \\
\hline \multicolumn{2}{|c|}{ Fluconazole } & 32 & 32 & 8 & 8 & 2 & 2 & 2 & 2 & 4 & 4 & 8 & 8 & 2 & 2 \\
\hline
\end{tabular}

The values are the mean of at least three determinations.

TABLE 3

Cytotoxicity of Compounds $4 \mathrm{a}, \mathbf{4 g}, 4 \mathrm{I}$, and 40 against Mouse Fibroblasts 3T3/NIH Cell after 24 and $48 \mathrm{~h}(\mu \mathrm{g} / \mathrm{mL})$

\begin{tabular}{ccccccccc}
\hline & \multicolumn{4}{c}{$\mathbf{2 4} \mathbf{h}$ (\% of Cell Viability) } & \multicolumn{4}{c}{$\mathbf{4 8} \mathbf{~}$ (\% of Cell Viability) } \\
\cline { 2 - 9 } & $\mathbf{1 0 0}$ & $\mathbf{5 0}$ & $\mathbf{2 5}$ & $\mathbf{1 2 . 7 5}$ & $\mathbf{1 0 0}$ & $\mathbf{5 0}$ & $\mathbf{2 5}$ & $\mathbf{1 2 . 7 5}$ \\
\hline $\mathbf{4 a}$ & 9 & 8 & 10 & 65 & 7 & 7 & 7 & 19 \\
$\mathbf{4 g}$ & 7 & 33 & 20 & 38 & 4 & 22 & 19 & 28 \\
$\mathbf{4}$ & 9 & 8 & 14 & 18 & 2 & 2 & 2 & 4 \\
$\mathbf{4 0}$ & 51 & 82 & 85 & 95 & 45 & 79 & 75 & 90 \\
\hline
\end{tabular}

The values are the mean of at least three determinations.

\section{Experimental}

Unless otherwise indicated, all reagents and solvents were used as obtained from commercial suppliers without further purification. ${ }^{1} \mathrm{H}$ spectra were recorded on a Bruker DRX 400 spectrometer $\left({ }^{1} \mathrm{H}\right.$ at 400.14 $\mathrm{MHz}$ ) in DMSO containing tetramethylsilane as an internal standard. Melting points were determined using open capillaries on a Fisatom model 430 apparatus and are uncorrected. The purity of compounds were confirmed by GC analyses in a Shimadzu Gas Chromatograph GC-2010 apparatus column HP-1 (column I.D., $0.25 \mathrm{~mm}$; column length, $30 \mathrm{~m}$; column head pressure, 14 psi; program: $\mathrm{T}_{0}=50^{\circ} \mathrm{C} ; \mathrm{t}_{0}=2.0$ $\min ;$ rate $16.0^{\circ} \mathrm{C} / \mathrm{min} ; \mathrm{T}_{\mathrm{f}}=250^{\circ} \mathrm{C} ; \mathrm{t}_{\mathrm{f}}=10.0 \mathrm{~min} ; \mathrm{Inj} .=250^{\circ} \mathrm{C} ;$ Det. $=270^{\circ} \mathrm{C}$ ).

\section{General Procedure for the Synthesis of 7-Chloro-4-Arylhydrazonequinolines 4a-0}

A mixture of 7-chloro-4-hydrazinoquinoline $2(2 \mathrm{mmol})$ and the appropriate arenealdehydes $3 \mathbf{a}-\mathbf{0}$ in toluene was heated at $110^{\circ} \mathrm{C}$ with a Dean-stark trap until reaction was complete, as shown by TLC (about $3 \mathrm{~h}$ ). After reaction time, the solvent was removed and the solid was washed with cold ethyl ether, leading to the hydrazones $\mathbf{4 a - 0}$ without any further purification.

\section{Antifungal Activity}

The antifungal assay was carried out following the CLSI M27-A3 (2008) method[23]. Hydrazones 4a-o were tested against 18 strains of eight species of oral yeasts: Candida albicans (8), $C$. parapsolisis (3), $C$. 
lipolytica (2), C. tropicalis (1), C. famata (1), C. glabrata (1), Rhodutorula mucilaginosa (1), and $R$. glutinis (1). The strains were obtained from the Laboratory of Oral Microbiology, Pelotas Dental School, at Federal University of Pelotas, Brazil. This study was approved by the Ethics Committee from Pelotas Dental School (Document nº. 036/2006).

\section{Sample Preparation}

The fungal suspensions were prepared by including a 24-h, previously activated strain in a test tube with 5 $\mathrm{mL}$ of sterile normal saline, adjusted to $0.5 \mathrm{McFarland}$ scale $\left(1.5 \times 10^{8}\right.$ microorganisms $\left./ \mathrm{mL}\right)$. The final inoculum contained $3.75 \times 10^{4}$ yeast cells $/ \mathrm{mL}$.

\section{The Test}

Ten dilutions of compounds $\mathbf{4 a - 0}$ were prepared with concentrations ranging from 0.2 to $104 \mu \mathrm{g} / \mathrm{mL}$ in DMSO. The fungal suspension was transferred in aliquots of $100 \mu \mathrm{L}$ into each well of the sterile plates containing $100 \mu \mathrm{L}$ of the compound dilution. Wells 11 and 12 were, respectively, the negative control ( $200 \mu \mathrm{L}$ of RPMI culture medium) and the positive control $(100 \mu \mathrm{L}$ of RPMI culture medium $+100 \mu \mathrm{L}$ of the fungal suspension). The plates were incubated at $37^{\circ} \mathrm{C}$ for $96 \mathrm{~h}$. The lowest concentration of the drug that produced the inhibition of the growth of the yeast was identified as the MIC value of the drug. To evaluate the MFC, $20 \mu \mathrm{L}$ of each solution that was considered a MIC concentration were plated onto a 9mm plate containing Sauboraud Dextrose Agar[24]. The MFCs were defined as the lowest drug dilutions that did not yield growth of yeast colonies (99.88\% killing activity) after $24 \mathrm{~h}$ of aerobic incubation at $37^{\circ} \mathrm{C}$. Fluconazole was used as reference compound[25,26].

\section{Cytotoxicity Assay}

The culture medium was obtained from GIBCO (Grand Island, NY, USA). All others reagents were from Sigma (Sigma Chemical Company, St. Louis, MO, USA). Compounds $\mathbf{4 a}, \mathbf{4 g}, \mathbf{4 l}$, and $\mathbf{4 o}$ were diluted in Dulbecco's modified Eagle's medium (DMEM). Series of dilutions were prepared, ranging between 12.75 and $100 \mu \mathrm{g} / \mathrm{mL}$ of a previous solution in DMSO. The cell culture medium was DMEM supplemented with $10 \%$ fetal bovine serum, $2 \%$ l-glutamine, penicillin $(100 \mathrm{U} / \mathrm{mL})$, and streptomycin $(100 \mathrm{mg} / \mathrm{mL})$. Mouse fibroblasts of the $3 \mathrm{~T} 3 / \mathrm{NIH}$ immortalized cell line were maintained as a stock culture in DMEM and incubated at $37^{\circ} \mathrm{C}$ in a humidified atmosphere of $5 \% \mathrm{CO}_{2}$ in air until subconfluency.

\section{Cytotoxicity Assay (MTT Assay)}

The 3-(4,5-dimethylthiazol-2-yl)-2,5-diphenyltetrazolium bromide (MTT) assay was used to assess cell metabolic function by mitochondrial dehydrogenase activity. Mouse fibroblasts 3T3/NIH $\left(2 \times 10^{4} /\right.$ well $)$ were maintained in DMEM in 96-well plates for $24 \mathrm{~h}$. Cytotoxicity produced by different dilutions of hydrazone derivatives was assessed in a 24- and 48-h cell-exposure time. After removing the test product, cells were washed with phosphate-buffered saline (PBS). Then $200 \mu \mathrm{L}$ of medium with $20 \mu \mathrm{L}$ of MTT solution $\left(5 \mathrm{mg} / \mathrm{mL}\right.$ MTT in PBS) was added to each well. After $5 \mathrm{~h}$ of incubation at $37^{\circ} \mathrm{C}$ in darkness, the blue formazan precipitation was extracted from the mitochondria using $200 \mu \mathrm{L} /$ well DMSO on a shaker for $5 \mathrm{~min}$ at $180 \mathrm{~g}$. The optical density at $540 \mathrm{~nm}$ was determined spectrophotometrically. All experiments were performed three times. 


\section{ACKNOWLEDGMENTS}

The authors thank Universidade Federal de Pelotas (UFPel) and Conselho Nacional de Desenvolvimento Científico e Tecnológico (CNPq) (proc. 305314/2009-2) for the financial support of the research. Coordenação de Aperfeiçoamento de Pessoal de Nível Superior (CAPES) and Fundação de Amparo à Pesquisa do Estado do Rio Grande do Sul (FAPERGS) are also acknowledged.

\section{REFERENCES AND NOTES}

1. Sautter, R.L. and Brown, W.J. (1980) Sequential vaginal cultures from normal young women. J. Clin. Microbiol. 11, 479-484.

2. Pfaller, M.A. and Diekema, D.J. (2007) Epidemiology of invasive candidiasis: a persistent public health problem. Clin. Microbiol. Rev. 20, 133-163.

3. Lund, R.G., Nascente, P.S., Etges, A., Ribeiro, G.A., Rosalen, P.L., and Del Pino, F.A.B (2010) Occurrence, isolation and differentiation of Candida spp. and prevalence of variables associated to chronic atrophic candidiasis. Mycoses $\mathbf{5 3}, 232-238$.

4. Lunardi, L.W., Aquino, V.R., Zimerman, R.A., and Goldani, L.Z. (2006) Epidemiology and outcome of Rhodotorula fungemia in a tertiary care hospital. Clin. Infect. Dis. 43, e60-63.

5. Cunico, W., Gomes, C.R.B., and Vellasco, W.T., Jr. (2008) Chemistry and biological activities of 1,3-thiazolidin-4ones. Mini-Rev. Org. Chem. 5, 336-344.

6. Rollas, S., Gülerman, N., and Erdeniz, H. (2002) Synthesis and antimicrobial activity of some new hydrazones of 4fluorobenzoic acid hydrazide and 3-acetyl-2,5-disubstituted-1,3,4-oxadiazolines. Farmaco 57, 171-174.

7. Vicini, P., Zani, F., Cozzini, P., and Doytchinova, I. (2002) Hydrazones of 1,2-benzisothiazole hydrazides: synthesis, antimicrobial activity and QSAR investigations. Eur. J. Med. Chem. 37, 553-564.

8. Loncle, C., Brunel, J., Vidal, N., Dherbomez, M., and Letourneux, Y. (2004) Synthesis and antifungal activity of cholesterol-hydrazone derivatives. Eur. J. Med. Chem. 39, 1067-1071.

9. Küçükgüzel, Ş.G., Oruç, E.E., Rollas, S., Şahin, F., and Özbek, A. (2002) Synthesis, characterization and biological activity of novel 4-thiazolidinones, 1,3,4-oxadiazoles and some related compounds. Eur. J. Med. Chem. 37, $197-206$.

10. Rollas, S. and Küçükgüzel, S.G. (2007) Biological activities of hydrazones derivatives. Molecules 12, $1910-1939$.

11. Fattorusso, C., Campiani, G., Kukreja, G., Persico, M., Butini, S., Romano, M.P., Altarelli, M., Ros, S., Brindisi, M., Savini, L., Novellino, E., Nacci, V., Fattorusso, E., Parapini, S., Basilico, N., Taramelli, D., Yardley, V., Croft, S., Borriello, M., and Gemma, S. (2008) Design, synthesis, and structure-activity relationship studies of 4-quinolinyland 9-acrydinylhydrazones as potent antimalarial agents. J. Med. Chem. 51, 1333-1343.

12. Kouznetsov, V.V. and Gómes-Barrio, A. (2009) Recent developments in the design and synthesis of hybrid molecules based on aminoquinoline ring and their antiplasmodial evaluation. Eur. J. Med. Chem. 44, 3091-3113.

13. Cunico, W., Cechinel, C.A., Bonacorso, H.G., Martins, M.A.P., Zanatta, N., de Souza, M.V.N., Freitas, I.O., Soares, R.P.P., and Krettli, A.U. (2006) Antimalarial activity of 4-(5-trifluoromethyl-1H-pyrazol-1-yl)-chloroquine analogues. Bioorg. Med. Chem. Lett. 16, 649-653.

14. Candéa, A.L.P., Ferreira, M.L., Pais, K.C., Cardoso, L.N.F., Kaiser, C.R., Henriques, M.G.M.O., Lourenço, M.C.S., Bezerra, F.A.F.M., and de Souza, M.V.N. (2009) Synthesis and antitubercular activity of 7-chloro-4quinolinylhydrazones derivatives. Bioorg. Med. Chem. Lett. 19, 6272-6274.

15. Ferreira, M.L., Goncalves, R.S.B., Cardoso, L.N.F., Kaiser, C.R., Candea, A.L.P., Henriques, M.G.M.O., Lourenco, M.C.S., Bezerra, F.A.F.M., and de Souza, M.V.N. (2010) Synthesis and antitubercular activity of heteroaromatic isonicotinoyl and 7-chloro-4-quinolinyl hydrazone derivatives. TheScientificWorldJOURNAL 10, 1347-1355.

16. Cunico, W., Capri, L.R., Gomes, C.R.B., Sizilio, R.H., and Wardell, S.M.S.V. (2006) An unexpected formation of 2aryl-3-benzyl-1,3-thiazolidin-4-ones. Synthesis 38, 3405-3408.

17. Cunico, W., Gomes, C.R.B., Ferreira, M.L.G., Capri, L.R., Soares, M., and Wardell, S.M.S.V. (2007) One-pot synthesis of 2-isopropyl-3-benzyl-1,3-thiazolidin-4-ones and 2-phenyl-3-isobutyl-1,3-thiazolidin-4-ones from valine, arenealdehydes and mercaptoacetic acid. Tetrahedron Lett. 48, 6217-6220.

18. Cunico, W., Vellasco, W.T., Jr., Moreth, M., and Gomes, C.R.B. (2008) Microwave-assisted synthesis of 1,3thiazolidin-4-ones and 2-aryl-1,3-oxathiolan-5-ones. Lett. Org. Chem. 5, 349-352.

19. Al-Sha'alan, N.H. (2007) Antimicrobial activity and spectral, magnetic and thermal studies of some transition metal complexes of a Schiff base hydrazone containing a quinoline moiety. Molecules 12, 1080-1091.

20. Selected ${ }^{1} \mathrm{H}$ NMR data for (E/Z)-7-chloro-4-[2-(4-methylbenzylidene)hydrazinyl]quinoline 4o: ${ }^{1} \mathrm{H} \mathrm{NMR}(400 \mathrm{MHz}$, DMSO): 11.18 (br, 1H); 8.57 (br, 1H); 8.36 (br, 2H); 7.89 (br, 1H); 7.68 (d, 2H, J = 8.1 Hz); 7.57 (br, $1 \mathrm{H}) ; 7.37$ (br, $1 \mathrm{H}) ; 7.27(\mathrm{~d}, 2 \mathrm{H}, J=8.1 \mathrm{~Hz}) ; 2.35\left(\mathrm{~s}, 3 \mathrm{H}, \mathrm{CH}_{3}\right)$.

21. Neuenfeldt, P.D., Drawanz, B.B., Siqueira, G.M., Gomes, C.R.B., Wardell, S.M.S.V., Flores, A.F.C., and Cunico, W. (2010) Efficient solvent-free synthesis of thiazolidin-4-ones from phenylhydrazine and 2,4-dinitrophenylhydrazine. Tetrahedron Lett. 51, 3106-3108. 
22. Neuenfeldt, P.D., Duval, A.R., Drawanz, B.B., Rosales, P.F., Gomes, C.R.B., Pereira, C.M.P., and Cunico, W. (2011) Efficient sonochemical synthesis of thiazolidinones from piperonilamine. Ultrasonics Sonochem. 18, 65-67.

23. Clinical and Laboratory Standards Institute Document M27-A3 (2008) Reference Method for Broth Dilution Antifungal Susceptibility Testing of Yeasts. Approved Standard. $3^{\text {rd }}$ ed.

24. Espinel-Ingroff, A., Fothergill, A., Peter, J., Rinaldi, M.G., and Walsh, T.J. (2002) Testing conditions for determination of minimum fungicidal concentrations of new and established antifungal agents for Aspergillus spp.: NCCLS collaborative study. J. Clin. Microbiol. 40, 3204-3208.

25. Costa, L.J., Birman, E.G., Alves, S.H., and Cury, A.E. (1999) Antifungal susceptibility of Candida albicans isolated from oral mucosa of patients with cancer. Rev. Odontol. Univ. São Paulo 13, 219-223.

26. Ito, C.Y.K., Martins, C.A.P., Loberto, J.C.S., Santos, S.S.F., and Jorge, A.O.C. (2004) In vitro antifungal susceptibility of Candida spp. isolates from patients with chronic periodontitis and from control patients. Braz. Oral Res. 18, 80-84.

\section{This article should be cited as follows:}

Duval, A.R., Carvalho, P.H., Soares, M.C., Gouvêa, D.P., Siqueira, G.M., Lund, R.G., and Cunico, W. (2011) 7Chloroquinolin-4-yl arylhydrazone derivatives: synthesis and antifungal activity. TheScientificWorldJOURNAL 11, 1489-1495. DOI 10.1100/tsw.2011.141. 

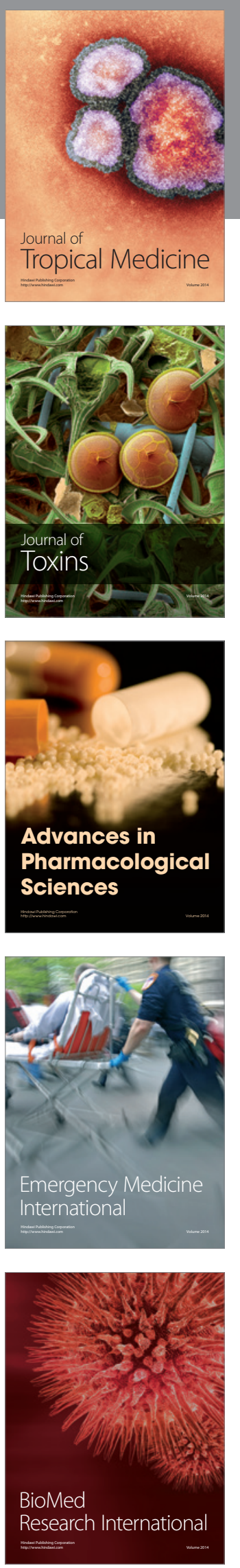
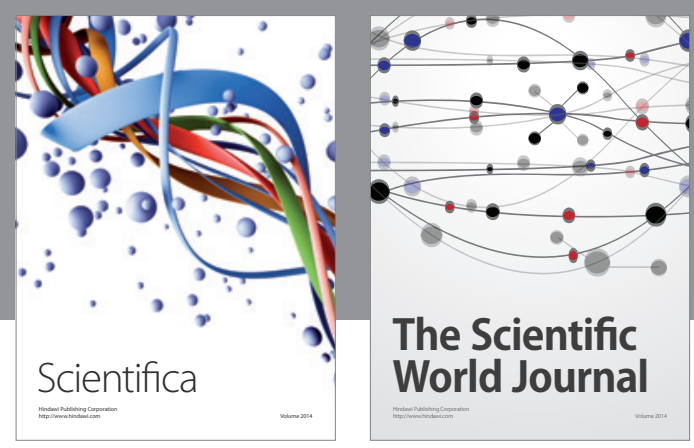

The Scientific World Journal
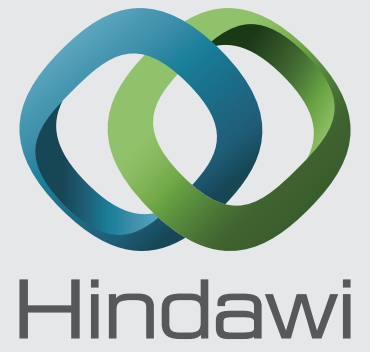

Submit your manuscripts at

http://www.hindawi.com
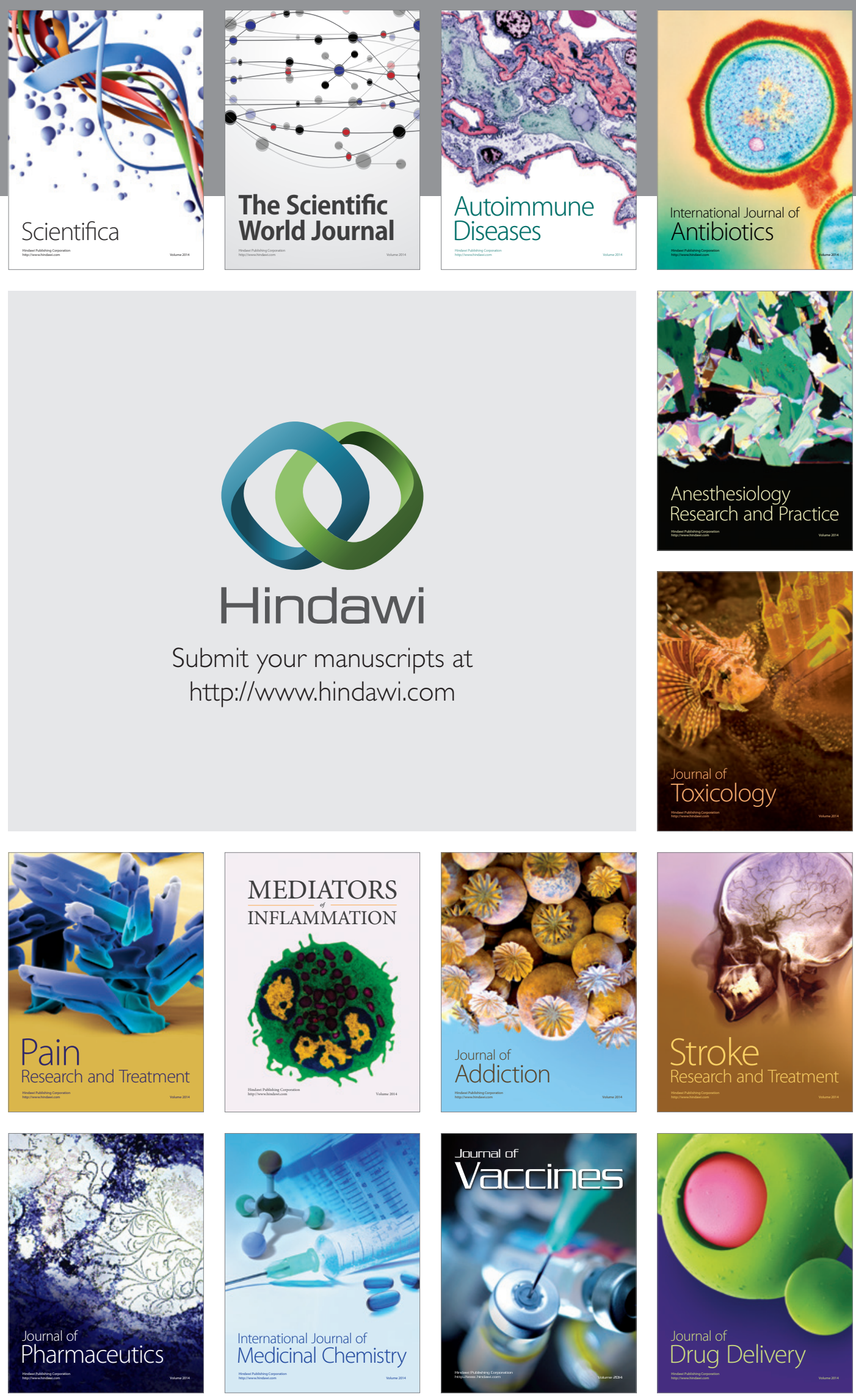